\title{
Detection and Analysis of Heavy Metals in Vegetables in Xinzhu Vegetable Base
}

\author{
Xiao-guang ZHAO \\ College of Geology and Environment \\ Xi'an University of Science and Technology \\ Xi'an, China \\ 13759991849@163.com \\ Meng-di GAO \\ College of Geology and Environment \\ Xi'an University of Science and Technology \\ Xi'an, China \\ 845788994@qq.com
}

\author{
Bing LI* \\ College of Geology and Environment \\ Xi'an University of Science and Technology \\ Xi'an, China \\ 18710996087@163.com \\ Yang LI \\ Shenhua Ningxia coal group \\ Yinchuan, China \\ 971126839@qq.com
}

\begin{abstract}
In order to study the pollution of heavy metals and the safety of vegetables in Baqiao district, $\mathrm{Xi}$ 'an, the contents of $\mathrm{Cu}, \mathrm{Zn}, \mathrm{Cr}$ and $\mathrm{Pb}$ in 8 fresh vegetables were determined. The results show that:(1)Most of the contents of heavy metals in vegetables in Xinzhu vegetable base did not exceed the standard, while $\mathbf{P b}$ is higher than national standards, which should be addressed; (2)The contents of heavy metals in eggplant vegetables was low, and the contents of heavy metals in leafy vegetables were higher; (3)By single factor pollution index evaluation method, 8 kinds of vegetables were not polluted by $\mathrm{Cu}, \mathrm{Zn}, \mathrm{Cr}$, three kinds of heavy metals, $\mathrm{Cr}$ content should be monitored; $\mathrm{Pb}$ content is very high, and it caused a serious pollution. Pepper and tomato can be obtained by Nemerow index method, the both of vegetables in the cordon, the index of eggplant, cucumber, chrysanthemum, romaine lettuce, Oilseed rape, tomato and leek belongs to light pollution, the relevant departments should immediately carry out pollution prevention and pollution treatment and corresponding action.
\end{abstract}

Keywords-Xinzhu vegetable base; Heavy metal; Single factor pollution index method; Nemero pollution index method.

\section{INTRODUCTION}

In recent years, Chinese agricultural environmental monitoring stations in Liaoning Province survey results show that heavy metals have caused some pollution to a variety of vegetables, exceeding the rate of up to $36.1 \%$, the area of pollution reached $3600 \mathrm{hm} 2[1]$. In the southern region of China, the main pollution of vegetables in Nanning city is from the Cr.

Xinzhu vegetable base is located in the Northern District of Baqiao, Xi'an, Shaanxi Province. The base is located next to the Xi'an Beltway and Port Road, vehicle exhaust emissions may increase the content of $\mathrm{Pb}$ in vegetables. Secondly, the new building street near the construction of four major heavy metals $\mathrm{Cu}, \mathrm{Pb}, \mathrm{Zn}, \mathrm{Cr}$, has the potential to build a vegetable base in $\mathrm{Cu}, \mathrm{Pb}, \mathrm{Zn}$, $\mathrm{Cr}$ content has a great impact.

\section{MATERIALS AND METHODS}

\section{A. Materials}

Vegetables were taken from Baqiao District, Xi'an City, the new town of vegetable base, a one-time acquisition of two categories of 8 varieties of 70 vegetable samples (Table I).

\section{B. Methods of Analysis}

The contents of heavy metals $\mathrm{Cu}, \mathrm{Zn}, \mathrm{Cr}, \mathrm{Pb}$ in cucumber, eggplant, tomato, pepper, romaine lettuce, leek, oilseed rape and chrysanthemum were measured by ultraviolet spectrophotometer. The experiment was divided into 5 steps, the collection of vegetable samples, the pretreatment of vegetable samples, the drawing of $\mathrm{Cu}, \mathrm{Zn}$, $\mathrm{Cr}, \mathrm{Pb}$ standard curve, the detection of vegetable sample digestion solution, the processing of the experimental data.

TABLE I. COLLECTION OF VEGETABLE VARIETIES AND THE NUMBER OF SAMPLES

\begin{tabular}{|c|c|c|}
\hline Vegetable varieties & vegetable type & Number of samples(unit) \\
\hline \multirow{4}{*}{ Eggplant } & eggplant & 2 \\
\cline { 2 - 3 } & Tomato & 4 \\
\cline { 2 - 3 } & Pepper & 8 \\
\cline { 2 - 3 } & Cucumber & 3 \\
\hline \multirow{4}{*}{ Leafy } & Chrysanthemum & 14 \\
\cline { 2 - 3 } & Romaine Lettuce & 12 \\
\cline { 2 - 3 } & Leek & 14 \\
\cline { 2 - 3 } & Oilseed rape & 13 \\
\hline
\end{tabular}




\section{EXPERIMENTAL RESULTS AND ANALYSIS}

\section{A. Data Processing}

According to the People's Republic of China international standard, "the safety and quality of agricultural products pollution-free vegetable safety requirements" (GB18406.1-2001), the experiment is to determine the limit of heavy metals in vegetables in the following Table II. After the samples were collected, the experiment was done, and every kind of heavy metal was measured three times, and the results were as Table III[2,3].

TABLE II.

CONTENTS OF HEAVY METALS IN VEGETABLES

\begin{tabular}{|c|c|c|c|c|}
\hline Heavy metal & Cu & Zn & Cr & Pb \\
\hline Maximum Limited (mg/kg) & 10 & 20 & 0.5 & 0.2 \\
\hline
\end{tabular}

\section{B. Results Analysis}

From the table we can see that the base of vegetables in the $\mathrm{Pb}$ content exceeded, and $\mathrm{Cu}, \mathrm{Zn}, \mathrm{Cr}$ content in the national standard below the normal range. Through the analysis of vegetable sampling sites, the concentration of $\mathrm{Pb}$ in vegetables was higher because the collection sites were near the highway and the traffic flow was large. Highway operation will cause heavy metal pollution in roadside soil and crops even if in rural areas which highway traffic is low, for some crops and farmland on both sides also produced pollution, Wang Chu[4] reported, in the premise of longterm operation under low traffic on both sides of the road in vegetable farming soil heavy metal pollution will occur in different degrees. The soil heavy metal pollution on both sides of the road in the range of $50 \mathrm{~m}$ is more obvious.

TABLE III. DETECTION RESULTS OF HEAVY METALS IN VEGETABLES WITH

\begin{tabular}{|c|c|c|c|c|c|}
\hline Vegetable & Project & $\begin{array}{l}\text { Content } \\
\text { (mg/kg) }\end{array}$ & $\begin{array}{l}\text { Detectio } \\
\text { n rate\% }\end{array}$ & $\begin{array}{l}\text { Exceeding } \\
\text { standard } \\
\text { rate } \% \\
\end{array}$ & $\begin{array}{c}\text { Average } \\
\text { content(mg/ } \\
\text { kg) }\end{array}$ \\
\hline \multirow{4}{*}{ eggplant } & $\mathrm{Cu}$ & $0.5 \sim 0.9$ & 100 & 0 & 0.667 \\
\hline & $Z n$ & $3.2 \sim 3.5$ & 100 & 0 & 3.4 \\
\hline & $\mathrm{Cr}$ & $0.2 \sim 0.34$ & 100 & 0 & 0.257 \\
\hline & $P b$ & $0.19 \sim 0.31$ & 100 & 80 & 0.25 \\
\hline \multirow{4}{*}{ tomato } & $\mathrm{Cu}$ & $0.6 \sim 1.1$ & 100 & 0 & 0.9 \\
\hline & $\mathrm{Zn}$ & $3.9 \sim 4.3$ & 100 & 0 & 4.133 \\
\hline & $\mathrm{Cr}$ & $0.22 \sim 0.36$ & 100 & 0 & 0.3 \\
\hline & $\mathrm{Pb}$ & $0.18 \sim 0.20$ & 100 & 20 & 0.193 \\
\hline \multirow{4}{*}{ pepper } & $\mathrm{Cu}$ & $1.0 \sim 1.1$ & 100 & 0 & 1.033 \\
\hline & $\mathrm{Zn}$ & $2.3 \sim 3.5$ & 100 & 0 & 2.833 \\
\hline & $\mathrm{Cr}$ & $0.15 \sim 0.20$ & 100 & 0 & 0.173 \\
\hline & $P b$ & $0.11 \sim 0.21$ & 100 & 40 & 0.153 \\
\hline Cucumber & $\mathrm{Cu}$ & $0.5 \sim 1.5$ & 100 & 0 & 1.067 \\
\hline
\end{tabular}

\begin{tabular}{|c|c|c|c|c|c|}
\hline & $Z n$ & $2.8 \sim 3.0$ & 100 & 0 & 2.933 \\
\hline & $\mathrm{Cr}$ & $0.20 \sim 0.22$ & 100 & 0 & 0.207 \\
\hline & $\mathrm{Pb}$ & $0.22 \sim 0.40$ & 100 & 100 & 0.283 \\
\hline \multirow{4}{*}{$\begin{array}{c}\text { Chrysanth- } \\
\text { emum }\end{array}$} & $\mathrm{Cu}$ & $1.7 \sim 2.0$ & 100 & 0 & 1.867 \\
\hline & $\mathrm{Zn}$ & $4.5 \sim 5.0$ & 100 & 0 & 4.733 \\
\hline & $\mathrm{Cr}$ & $0.29 \sim 0.35$ & 100 & 0 & 0.323 \\
\hline & $\mathrm{Pb}$ & $0.30 \sim 0.34$ & 100 & 100 & 0.323 \\
\hline \multirow{4}{*}{$\begin{array}{l}\text { romaine } \\
\text { lettuce }\end{array}$} & $\mathrm{Cu}$ & $1.5 \sim 1.9$ & 100 & 0 & 1.633 \\
\hline & $\mathrm{Zn}$ & $4.7 \sim 4.8$ & 100 & 0 & 4.733 \\
\hline & $\mathrm{Cr}$ & $0.22 \sim 0.40$ & 100 & 0 & 0.29 \\
\hline & $\mathrm{Pb}$ & $0.22 \sim 0.40$ & 100 & 100 & 0.323 \\
\hline \multirow{4}{*}{ leeks } & $\mathrm{Cu}$ & $1.9 \sim 2.1$ & 100 & 0 & 2.067 \\
\hline & $\mathrm{Zn}$ & $4.4 \sim 5.1$ & 100 & 0 & 4.833 \\
\hline & $\mathrm{Cr}$ & $0.33 \sim 0.37$ & 100 & 0 & 0.347 \\
\hline & $\mathrm{Pb}$ & $0.28 \sim 0.34$ & 100 & 100 & 0.317 \\
\hline \multirow{4}{*}{ Oilseed rape } & $\mathrm{Cu}$ & $1.3 \sim 1.8$ & 100 & 0 & 1.633 \\
\hline & $Z n$ & $3.9 \sim 4.6$ & 100 & 0 & 4.167 \\
\hline & $\mathrm{Cr}$ & $0.34 \sim 0.34$ & 100 & 0 & 0.34 \\
\hline & $\mathrm{Pb}$ & $0.25 \sim 0.37$ & 100 & 100 & 0.307 \\
\hline
\end{tabular}

The average $\mathrm{Cd}$ and $\mathrm{Pb}$ concentrations in vegetable soils were $21.0 \%$ and $2.9 \%$ (moderate and severe pollution), respectively. The average $\mathrm{Pb}$ exceeded standard of roadside vegetables was $43.2 \%$ and that of $\mathrm{Cd}$ was $18.6 \%$. The average content of heavy metal in roadside dust was significantly higher Roadside soil, roadside soil and vegetables is a potential source of pollution. This can be learned that the new vegetable base of vegetables in the $\mathrm{Pb}$ content exceeded the surrounding road vehicle exhaust gas caused by the $\mathrm{Pb}$. Baqiao new vegetable base near the Bahe River, there is no heavy industry around, so the rest of the heavy metal content less[5].

The results showed that the heavy metal contents in leafy vegetables were higher than those in eggplant fruits and vegetables, mainly due to the distance of the vegetables from the roots and the migration of heavy metals. Therefore, the content of heavy metals in the vegetables was lower than that of the leafy vegetables Class vegetables, which Wang Lifeng study consistent with the results[6].

1) Single factor evaluation analysis

The results of Table IV show that the content of $\mathrm{Cu}$ and $\mathrm{Zn}$ is very low, and the $\mathrm{Pi}$ value is much lower than 1 , indicating that these two kinds of heavy metals have not been polluted. The $\mathrm{Cr}$ value of $\mathrm{Pi}$ does not reach 1 , indicating that there is no pollution, but its value relative to the former two large, should be monitored. The content of $\mathrm{Pb}$ in the table is more than 1 , indicating that the eight kinds of vegetables by the $\mathrm{Pb}$ pollution, the maximum value of 
1.85, indicating that has been at a relatively high level, by the pollution is very serious[7,8].

TABLE IV. EVALUATION OF SINGLE POLLUTION INDEX

\begin{tabular}{|c|c|c|c|c|}
\hline Vegetable species & $\mathbf{C u}$ & Zn & $\mathrm{Cr}$ & $\mathbf{P b}$ \\
\hline \multirow{3}{*}{ Eggplant } & 0.05 & 0.16 & 0.4 & 1.55 \\
\hline & 0.09 & 0.175 & 0.46 & 0.95 \\
\hline & 0.06 & 0.175 & 0.68 & 1.25 \\
\hline \multirow{3}{*}{ Tomato } & 0.11 & 0.215 & 0.64 & 0.9 \\
\hline & 0.1 & 0.21 & 0.44 & 1 \\
\hline & 0.06 & 0.195 & 0.72 & 1 \\
\hline \multirow{3}{*}{ Pepper } & 0.1 & 0.175 & 0.3 & 1.05 \\
\hline & 0.1 & 0.115 & 0.34 & 0.55 \\
\hline & 0.11 & 0.135 & 0.4 & 0.7 \\
\hline \multirow{3}{*}{ Cucumber } & 0.15 & 0.14 & 0.4 & 1.1 \\
\hline & 0.12 & 0.15 & 0.4 & 1.15 \\
\hline & 0.05 & 0.15 & 0.44 & 2 \\
\hline \multirow{3}{*}{ Chrysanthemum } & 0.17 & 0.225 & 0.7 & 1.7 \\
\hline & 0.19 & 0.235 & 0.66 & 1.65 \\
\hline & 0.2 & 0.25 & 0.58 & 1.5 \\
\hline \multirow{3}{*}{ Romaine Lettuce } & 0.15 & 0.235 & 0.44 & 2 \\
\hline & 0.15 & 0.24 & 0.5 & 1.75 \\
\hline & 0.19 & 0.235 & 0.8 & 1.1 \\
\hline \multirow{3}{*}{ Leek } & 0.19 & 0.25 & 0.74 & 1.4 \\
\hline & 0.22 & 0.255 & 0.68 & 1.65 \\
\hline & 0.21 & 0.22 & 0.66 & 1.7 \\
\hline \multirow{3}{*}{ Oilseed rape } & 0.18 & 0.23 & 0.68 & 1.25 \\
\hline & 0.18 & 0.2 & 0.68 & 1.5 \\
\hline & 0.13 & 0.195 & 0.68 & 1.85 \\
\hline
\end{tabular}

\section{2) Multi-factor evaluation analysis}

In this paper, the Nemerow index method is used. Pi is the average pollution index of heavy metals in vegetables, $\mathrm{Pi}$ max is the maximum pollution index of heavy metals in vegetables, and $\mathrm{P}_{\text {neomei }}$ is the pollution index of Nemero.

The Nemerow index was calculated to be $0.7,0.7$ to 1.0 , 1.0 to $2.0,2.0$ to 3.0, and 3.0, respectively, for heavy metal content in vegetables: safety, cordon, light pollution, heavy pollution and heavy pollution.

It can be concluded from Table $\mathrm{V}$ that the Nemerow index of tomatoes and peppers is 0.780064 and 0.780326 , respectively, in the range of 0.7 to 1.0 in eggplant, tomato, pepper, cucumber, and chrysanthemum, lettuce, leek and oilseed rape. Two vegetables in the cordon, should be sustained attention, and do the appropriate preventive measures. While the eggplant, cucumber, chrysanthemum, lettuce, Oilseed rape, leek, Nemerow index were 1.15, 1.16, $1.29,1.29,1.48,1.38$, in the range of 1.0 to 2.0 , belonging to mild pollution, the relevant departments should be carried out immediately Pollution control and pollution treatment and other corresponding actions[9,10].In general, the Nemerow index of heavy metals in vegetables is lower than that of the heavy metals in leafy vegetables, which indicates that the pollution of eggplant vegetables is less than that of leafy vegetables.

TABLE V. NEMERO INDEX OF POLLUTION EVALUATION TABLE

\begin{tabular}{|c|c|c|c|}
\hline Vegetable species & Nemerow index & Vegetable species & Nemerow index \\
\hline Eggplant & 1.151629 & Chrysanthemum & 1.292505 \\
\hline Tomatoes & 0.780064 & Leek & 1.29501 \\
\hline Cucumber & 1.161381 & lettuce & 1.486845 \\
\hline Pepper & 0.780326 & Oilseed rape & 1.385666 \\
\hline
\end{tabular}

\section{CONCLUSION}

- Baqiao new building vegetable base, most of the heavy metal content of vegetables did not exceed the standard, only the content of $\mathrm{Pb}$ higher than the national standard should be addressed.

- Solanaceous vegetables in the low content of heavy metals; leafy vegetables, high levels of heavy metals in vegetables.

- $\quad$ Eight kinds of vegetables were not contaminated by $\mathrm{Cu}, \mathrm{Zn}$ and $\mathrm{Cr}$, Cr content should be monitored; $\mathrm{Pb}$ content was very high, and the pollution was serious.

\section{REFERENCES}

[1] Yong Zhang,"Survey of Heavy Metals Pollution in Soils and Agricultural Products in Suburbs of Shenyang,"Journal of Soil Science.J. China, vol.4, pp.182-186,2001.

[2] Dan-Li Xi, Yu-sheng Sun."Environmental Monitoring (Fourth Edition)." Higher Education Press.M.Beijing, pp.86-88,2010.

[3] Qian Jin, Rui-bo Liu, Hao-lin Mu, "Determination of heavy metals in vegetables in supermarkets," Journal of Zunyi Normal University.J. China, vol.5, pp.71-73, 2008.

[4] Li-feng Wang, Jun-gui Bai,"Investigation and Control of Vegetable Pollution in Shenyang,"Journal of Agricultural Environmental Protection.J.China, vol.2, pp.84-88, 1994.

[5] Chu Wang, Zhen-lou Chen, Jing Wang,"Chongming Island road on both sides of vegetable soil and vegetable heavy metal pollution," Journal of ecological and agricultural environment.J.China,vol.2, pp.89-93,2007.

[6] Xiu-hong Tian,"Progress of Heavy Metal Pollution in Vegetables in Suburbs of China,"Food Science.J.China,vol.20,pp.449-453,2009.

[7] Li-xia Yao, Qiao-mei Ru, Liang-xing He,"Advances in Research on Metal Contamination in Vegetables,"Modern Agricultural Science and Technology.J.China,vol.22,pp.208-210,2013.

[8] Xu Wang."Risk Assessment of Heavy Metals in Vegetables in Guangdong," Huazhong Agricultural University.D.China,2012.

[9] Fei Yin, Jing Wang,"Analysis and Evaluation of Heavy Metal Pollution of Listed Vegetables in Kashi,"Anhui Agricultural Sciences.J.China,vol.23,pp.12671-12672,2010.

[10] Wen-zhe Ma,Wen-guang Wang,Chun-xia Wu,"Analysis and Evaluation of Heavy Metal Pollution in Vegetables in Yangling Demonstration Area,"Northern Horticulture.J.China,vol.17, pp.4648,2012 . 